\title{
Stress, Anxiety, Binge Drinking, and Substance Use Among College Student- Athletes: A Cross-Sectional Analysis
}

\author{
Brandon A. Knettel ${ }^{1}$, Emily M. Cherenack ${ }^{1}$, and \\ Courtney Bianchi-Rossi
}

${ }^{1}$ Duke University, ${ }^{2}$ Bethel University

\begin{abstract}
Student-athletes face considerable stress in balancing participation in sports with other responsibilities, which can contribute to unhealthy coping behaviors including alcohol and drug use. We administered online surveys to 188 college athletes to examine stress, athletics-related anxiety, and perceived control of stress as predictors of binge drinking, substance use, and associated risk behaviors. Participants rated athletics as the second greatest source of stress in their lives, trailing only academics. Athletics-related anxiety was associated with significantly higher cannabis use and substance-related risk behaviors and represents an understudied area in the literature. Reports of alcohol and drug use in our sample were comparable to national surveys of student-athletes, but opioid misuse was troublingly high. Participants over the age of 21 and males were more likely to report substance use and risk behaviors. Athletes are susceptible to orthopedic injury and associated pain, which may lead to early exposure to opioids with high potential for abuse. Interventions for this population must target social contributors to substance use among student-athletes, opioid prescription and misuse as a gateway to opioid use disorders, and untreated anxiety as a potential driver of substance use, including anxiety associated with athletic performance.
\end{abstract}

Keywords: Alcohol use disorder, Alcoholism, Alcohol drinking, Cannabis, Risk-Taking, Sports, Students, Substance use, Substance-related disorders

\section{Background}

The immense stress faced by college students as they navigate multiple responsibilities and pressures can contribute to unhealthy coping behaviors including alcohol and drug use (Auerbach et al., 2018). Student-athletes may face unique challenges related to their need to balance the academic and interpersonal stressors common to all students with the additional pressures of competition and training (Brown et al., 2014; Hatteberg, 2020; Papanikolaou et al., 2003). Students whose financial well-being is tied to their athletic performance, including scholarship ath- 
letes or those aspiring to compete professionally, may face even higher pressures (Judge et al., 2012). As alcohol and other substance use are common in the social culture of some collegiate athletics teams, athletes may also face social pressure to use substances (Graupensperger et al., 2018; Parisi et al., 2019).

Two systematic reviews found that both male and female student-athletes are more likely to abuse alcohol and experience alcohol-related problems compared to their non-athlete peers, but are less likely to use marijuana and illicit drugs (Kwan et al., 2014; Lisha \& Sussman, 2010; Parisi et al., 2019); however, rates of substance use and abuse are unacceptably high in this population. In relevant studies, $34 \%$ of student-athletes self-reported binge drinking in the prior two weeks (Lewis et al., 2017), 28\% reported using cannabis during the prior year (Reardon \& Creado, 2014), and between 1-4\% reported using cocaine, MDMA (aka "ecstasy" or "molly"), hallucinogens, and amphetamines during the prior year (NCAA, 2018a). Athletes also commonly engage in high-risk behaviors while intoxicated, such as drinking and driving, at rates similar to their non-athlete peers (Bastien et al., 2019).

There has been a notable evolution in patterns of substance abuse among college athletes over the past 20 years. Traditionally common substances of abuse such as alcohol and marijuana have increasingly become paired with designer drugs such as MDMA, and there has been a recent resurgence in cocaine use (NCAA, 2018a). Other drugs have become more widespread as well, including so-called "study drugs" or "ADHD stimulants" such as Adderall and Ritalin, which are used by student-athletes to get high or in an effort to improve academic performance (Buckman et al., 2013; Sepúlveda et al., 2011).

Further, there has been a national epidemic of prescription opioid abuse, leading to a six-fold increase in opioid-related overdose deaths among adults since 1999; these drugs now account for more than two-thirds of all overdose deaths in the United States and disproportionately affect the young adult population (Scholl et al., 2019). Student-athletes are susceptible to orthopedic injuries, which may lead to increased risk of opioid abuse and dependence (Reardon \& Creado, 2014). Opioids initially prescribed to manage pain may contribute to increased vulnerability for abuse and addiction (Veliz et al., 2017). One national survey of college-age youth found that $16 \%$ had abused pain medication, and this number was significantly greater $(23 \%)$ among student-athletes (Hazelden Betty Ford Foundation, 2015).

Student-athletes face unique stressors compared to their non-athlete peers, which may be a key contributor to substance use and emotional distress in this population. Many college students must balance academic performance, social demands, adjusting to life away from home, and financial challenges, and collegiate athletes face additional commitments of time and energy for practices, team meetings, travel, and competition (Lopes Dos Santos et al., 2020; Paule \& Gilson, 2010).

Emotional distress is less common among student-athletes than their non-athlete peers; however, a multi-year, national survey of 19,733 US student-athletes found high prevalence of self-reported depression (21\% male, $28 \%$ female) and anxiety $(31 \%$ male, $48 \%)$ in this population. Perceived stress was the single largest predictor of emotional distress among student-athletes in this study (Brown et al., 2014). Ad- 
ditionally, student-athletes experiencing emotional distress are less likely than their peers to seek professional support (Bird, Chow, \& Yang, 2020; Kern et al., 2017), often due to time constraints and concerns about stigma (Bird, Chow, \& Cooper, 2020).

De Grace and colleagues (2017) highlighted the role of athletic participation as a potential risk factor for substance abuse. In their interviews with adults in recovery, participants who had been involved in organized sports frequently cited the overlap between substance use and the social connection of athletic participation as well as the use of substances as a means of coping with the physical and emotional demands of athletics. In recent years, data have become much more readily available on patterns of substance use among college students, including student-athletes; however, relatively few studies have attempted to assess relationships between athletics-related stress and substance use as a form of maladaptive coping. In addition, an individual's perception of their control in managing a situation has been found to be a key factor in coping, and perceptions of behavioral control are central to the science of addiction (Dijkstra \& Homan, 2016; National Institute on Drug Abuse, 2020). As such, additional research is needed to examine perceived control among student-athletes.

Furthermore, prior research suggests personal and demographic variables may be associated with substance use and physical activity. For example, gender and age have been shown to moderate the relationship between alcohol use and physical activity (Boyes et al., 2017; Lisha et al., 2011) and grade point average (GPA) has also been correlated with substance use in college students (Ford \& Arrastia, 2008).

The purpose of the current study was to gain a clearer understanding of various stressors experienced by student-athletes and their relationship with substance use. To achieve these aims, we surveyed student-athletes in order to describe their patterns of substance use, experiences of physical pain, perceptions of athletics-related stressors in comparison to other forms of stress in their lives, and the association of these with (a) substance use, including alcohol, marijuana, and other substances; and (b) risk behaviors associated with substance use.

\section{Methods}

\section{Procedure}

We contacted the athletics departments at colleges and universities in five Upper Midwest states (Iowa, Minnesota, North Dakota, South Dakota, Wisconsin) with athletics teams competing throughout the National Collegiate Athletic Association (NCAA; i.e., Division I, II, III), and National Junior College Athletic Association (NJCAA) levels. Emails were sent to athletics departments introducing the research and requesting permission to send an invitation to participate to the institution's full student-athlete listserv. All invitations to participate were sent during the traditional fall and spring semesters and included a link to an online survey examining sources of stress, drinking, and substance use.

Six colleges and universities agreed to participate in the research, representing $55 \%$ of those invited, including two public universities competing at the Division 
I level, two public universities competing at the Division II level, one private college competing at the Division III level, and one NJCAA community college. Five departments sent email invitations (including a link to the online survey) to their student-athletes via email listservs; one university included the invitation and link in a weekly email newsletter sent to all student-athletes. The invitations included the study inclusion criteria that all participants were required to be 18 years of age or older, attending a college/university, and a member of one or more varsity athletic teams at their university during the current academic year. It is important to note that at the time of the surveys, the use of medical marijuana/cannabis (with a physician's prescription) was legal in two of the states where participating universities were located; however, recreational use was illegal in all participating states and marijuana is considered a banned substance for all athletes by the NCAA, even when used legally or medically prescribed.

Respondents who accessed the survey website completed informed consent prior to participating by checking a box indicating their understanding and agreement. No names or other personally identifying information were collected on the internet survey, which took approximately 15-20 minutes to complete. Informed consent was provided by 225 participants, of whom 197 (87.6\%) completed the survey. Three validity check items were included in the survey (e.g., "For this item, please choose Option 2, 'A little bit stressful'") to identify participants who were not appropriately attending to the items. Nine participants $(4.6 \%)$ were excluded for failing one or more of the validity check items, resulting in a final sample of 188 participants. Five of the six college/universities provided data on the total number of students who received the invitation to participate. Among the 1613 student-athletes at these institutions, we obtained a $9.8 \%$ response rate.

At the conclusion of the survey, participants were provided the option to register for a random drawing for three $\$ 50$ gift cards in accordance with NCAA bylaw 16.11.1.11.2. Those who wished to enter the drawing clicked a link for a separate online form where they provided an email address. Thus, the email address was not linkable to the study data. All data were password-protected and accessible only by the research team. Study procedures received ethical approval from the institutional review board at Gustavus Adolphus College.

\section{Measures}

Demographic and Background Data. The study survey began by asking participants to provide relevant demographic information and background data, including their age, gender, race, year in school, grade point average (GPA), sexual orientation, socioeconomic status, and sport(s) as well as the NCAA/NJCAA division of their athletics team(s).

Sources of Stress. A measure of sources of stress specific to university students was adapted from The Graduate Stress Inventory (GSI; Rocha-Singh, 1994). It included two preliminary questions: "Overall, how stressful are you finding university?" and "In general, how have you been coping with your university-related stress?" Students were presented with items listing 12 different sources of stress (e.g., aca- 
demics, finances, social relationships, athletics) and asked to rate how stressful each event was in their lives. These 12 items were answered on a scale of 1 ("Not at all stressful") to 5 ("Extremely stressful") and summed for a total score of 12 to 48 $($ Alpha $=.823)$.

Athletics-Related Anxiety. Thirteen items from the Sport Anxiety Scale (SAS2; Smith et al., 2006) were used to assess symptoms of anxiety experienced during athletic competition, including feelings of worry, difficulty concentrating, or physical symptoms (e.g., muscle tightness, uneasy stomach). Items were rated on a four-point scale from "not at all" to "very much" for a total score of 13 to 52 (Alpha = .909).

Physical Pain. To assess symptoms of physical pain, we used items from the Short-Form McGill Pain Questionnaire (SF-MPQ; Melzack, 1987). Participants were asked whether they had experienced any pain from an injury sustained in the past month during athletics. If they answered "yes," they were asked to rate both their pain today and their pain on a typical day during the past month on a scale of 0 ("no pain") to 5 ("excruciating").

Perceived Control. We used 4 items from the Perceived Control Questionnaire (PCQ; Kowalski, 2000; Kowalski \& Crocker, 2001) to assess self-rated control over stress related to participation in athletics. Items were rated on a scale of 1 ("strongly disagree") to 5 ("strongly agree") with higher ratings indicating more perceived control (Alpha = .767).

Substance use. Participants' use of alcohol and other drugs was assessed using three measures: (1) the CRAFFT Screening Test (Knight et al., 2002), (2) the NIDA-Modified ASSIST V2.0 (National Institute on Drug Abuse, 2012), and (3) the brief form of the Alcohol Use Disorders Identification Test (AUDIT-C; Bush et al. 1998). The CRAFFT consists of 9 yes/no questions examining the use of alcohol and other substances in the past 12 months and the lifetime incidence of risk behaviors associated with alcohol and drug use (e.g., driving or riding in a car with someone who had been using, forgetting things that happened while using alcohol or drugs). Each item was scored 0 ("No") or 1 ("Yes") for a total score of 0 to 9, with a higher score indicating greater risk behavior. The ASSIST was used to assess lifetime illicit or not-prescribed use (yes/no) of various categories of substances: cannabis, cocaine, prescription opioids (e.g., Percocet, Vicodin), prescription stimulants (e.g., Adderall, Ritalin), and hallucinogens (e.g., MDMA/Ecstasy, LSD, mushrooms). The AUDIT-C consists of three questions assessing the frequency of alcohol use, the amount of daily consumption, and the frequency of binge drinking (defined as having six or more drinks on one occasion) on a scale of 1 ("Never") to 5 ("Daily or almost daily") for a total score ranging from 3 to 15 .

\section{Data Analysis}

We used simple frequencies and descriptive statistics to summarize participant characteristics including frequency of substance use, physical pain, and sources of stress. For multi-item scales, missing items were imputed with the individual mean of completed items when at least $75 \%$ of items were completed (Downey \& King, 1998; Shrive et al., 2006). Significant intercorrelations were common among the contin- 
uous predictor variables but none exceeded pre-identified thresholds for multicollinearity $(r>.80$ or VIF $>5.0)$ (Kutner et al., 2013).

To examine correlates of alcohol and drug use, we performed four regression models assessing participant gender, age, grade point average, self-rated stress level, athletics-related anxiety, physical pain in the past month, and perceived control of stressors as independent variables associated with the following dependent variables: (1) binge drinking in the past month, (2) cannabis use in the past 12 months, (3) lifetime use of any other substance, and (4) the number of variables endorsed on the CRAFFT, indicating alcohol- and drug-related risk behaviors. The first three models used binary logistic regression, and the fourth model used Poisson regression with robust variance.

\section{Results}

\section{Participants}

Participants in the study were 188 student-athletes. The majority of participants self-identified as women $(n=142,75.5 \%)$, and the mean age was 20 years, with a fairly even distribution among ages 18-22 and a small number of participants aged 23-25 $(n=6)$. The mean grade point average was 3.4 on a 4.0 scale. Participants in the sample were predominantly white $(n=165,87.8 \%)$. In total, 66 student-athletes $(35.1 \%)$ competed at the NCAA Division I level, 48 (25.5\%) competed at the NCAA Division II level, 63 (33.5\%) competed at the NCAA Division III level, and $11(5.9 \%)$ competed at the NJCAA/Community College level. Additional details and participant characteristics are reported in Table 1.

\section{Table 1}

Characteristics of Study Participants

\begin{tabular}{|l|r|}
\hline Category & Value (\%) \\
\hline Total Participants & 188 \\
\hline Gender & $142(75.5 \%)$ \\
\hline Women & $46(24.5 \%)$ \\
\hline Men & 20 years \\
\hline Mean Age & \\
\hline Racial Identity (self-identified) & $165(87.8 \%)$ \\
\hline White & $8(4.3 \%)$ \\
\hline Multiracial/Mixed & $4(2.1 \%)$ \\
\hline Black/African American & $3(1.6 \%)$ \\
\hline Non-White Hispanic/Latino & $2(1.1 \%)$ \\
\hline Asian & $2(1.1 \%)$ \\
\hline Native American & \\
\hline
\end{tabular}


Table 1, continued

Characteristics of Study Participants

\begin{tabular}{|l|r|}
\hline Sexual Orientation (self-identified) & \\
\hline Straight/Heterosexual & $181(96.3 \%)$ \\
\hline Gay or Lesbian & $5(2.7 \%)$ \\
\hline Unsure & $2(1.1 \%)$ \\
\hline Annual Family Income & $23(12.2 \%)$ \\
\hline Above \$200,000 & $82(43.6 \%)$ \\
\hline \$100,001-200,000 & $34(18.1 \%)$ \\
\hline \$75,001-100,000 & $27(14.4 \%)$ \\
\hline \$50,001-75,000 & $10(5.3 \%)$ \\
\hline \$25,000-50,000 & $12(6.4 \%)$ \\
\hline Below \$25,000 & \\
\hline Year in School & $59(31.4 \%)$ \\
\hline First Year & $46(24.5 \%)$ \\
\hline Second Year & $42(22.3 \%$ \\
\hline Third Year & $38(20.2 \%)$ \\
\hline Fourth Year & $3(1.6 \%)$ \\
\hline Fifth Year / Other & $18(9.6 \%)$ \\
\hline Sport (Top 7 Most Common) & $16(8.5 \%)$ \\
\hline Track \& Field & $15(8.0 \%)$ \\
\hline Softball & $13(6.9 \%)$ \\
\hline Soccer & $50(26.6 \%)$ \\
\hline Cross Country & $26(13.8 \%)$ \\
\hline Volleyball & $18.6 \%)$ \\
\hline Swimming/Diving & \\
\hline Tennis & \\
\hline Level of Competition & \\
\hline NCAA Division I & \\
\hline NCAA Division II & \\
\hline NCAA Division III & \\
\hline NJCAA/Community College & \\
\hline
\end{tabular}


Table 1, continued

Characteristics of Study Participants

\begin{tabular}{|l|r|}
\hline Stress of Attending College & $1(0.5 \%)$ \\
\hline Not at all & $23(12.2 \%)$ \\
\hline A little bit & $102(54.3 \%)$ \\
\hline Moderate & $56(29.8 \%)$ \\
\hline Very Stressful & $6(3.2 \%)$ \\
\hline Extremely Stressful & \\
\hline Coping with Stress & $5(2.7 \%)$ \\
\hline Not well at all & $48(25.5 \%)$ \\
\hline A little & $71(37.8 \%)$ \\
\hline Satisfactorily & $55(29.3 \%)$ \\
\hline Coping well & $9(4.8 \%)$ \\
\hline Coping extremely well & \\
\hline
\end{tabular}

\section{Substance Use}

A large majority of participants (86.1\%; male 92.3\%, female $84.0 \%$ ) had taken "more than a few sips" of alcohol in the past year, and 15.0\% endorsed drinking 2-3 times per week or more (male $15.6 \%$, female $10.7 \%$ ). In total, $27.8 \%$ of participants reported binge drinking at least monthly, including $44.7 \%$ of male respondents and $22.5 \%$ of female respondents.

More than one-third of participants (38.1\%; male 48.7\%, female 34.7\%) reported having used cannabis at some point in their lifetime, and $22 \%$ had used cannabis in the past year (male 30.8\%, female 19.2\%). Nearly one-quarter of participants (23.4\%) male $37.0 \%$, female $19.0 \%$ ) reported using a substance other than alcohol or cannabis at some point in their lifetime; however, only $2.5 \%$ (male $7.7 \%$, female $0.8 \%$ ) reported using a substance other than alcohol or cannabis "to get high" in the past year. The most common drugs of abuse aside from alcohol and cannabis were prescription opioids (e.g., Percocet, Vicodin, [11.9\% lifetime use; male 17.9\%, female 9.9\%]); prescription stimulants (e.g., Adderall, Ritalin, [11.3\% lifetime use; male 15.4\%, female 9.9\%]); hallucinogens (e.g., MDMA/Ecstasy, LSD, mushrooms, [5.0\% lifetime use; male $12.8 \%$, female $2.5 \%]$ ); and cocaine ( $4.4 \%$ lifetime use; male $12.8 \%$, female $1.7 \%$ ).

In exploring alcohol- and drug-related risk behaviors, $40.9 \%$ (male $51.3 \%$, female $37.5 \%$ ) of participants had used alcohol or drugs "to relax, feel better about yourself, or fit in"; $28.3 \%$ (male $33.3 \%$, female $26.7 \%$ ) had forgotten things they had done while using alcohol or drugs; $23.3 \%$ (male $33.3 \%$, female $20.0 \%$ ) had driven while using or had ridden in a car with someone who was using; and $23.3 \%$ (male $46.2 \%$, female $15.8 \%$ ) had used alcohol or drugs while alone. Far fewer participants 
reported getting into trouble for alcohol or drug use $(12.0 \%$; male $15.4 \%$, female $10.9 \%)$ or having someone tell them they should cut down on their use $(2.5 \%$; male $2.6 \%$, female $2.5 \%$ ).

\section{Pain}

More than half of participants $(n=108,57.4 \%)$ reported they had experienced physical pain during the past 30 days from an injury sustained while participating in athletics. When asked to rate their pain on a typical day in the last month, the majority of participants described their pain as "discomforting" $(n=71,39.0 \%)$ or "distressing" $(n=39,21.4 \%)$, while only 33 participants $(18.1 \%)$ said they had no pain on a typical day in the last month.

\section{Sources of Stress}

On average, participants described their university experience as "moderately stressful" (mean=3.23 out of 5, SD=.721) and rated themselves as coping "satisfactorily" (mean $=3.08$ out of $5, \mathrm{SD}=.919$ ). In examining various sources of stress in their lives, participants rated athletics as the second most stressful aspect of their college experience (mean=3.37), exceeded only by academic stress (mean=3.51) among the 12 items. Time management (mean=3.15), emotional health (mean=3.01), and finances (mean=2.92) were the next most highly rated stressors, while relationships with family (mean=2.18) and college faculty/staff (mean=1.85) were lowest on the list (see Figure 1).

\section{Factors Associated with Binge Drinking, Cannabis Use, and Other Substance Use}

In univariable analyses assessing the factors associated with binge drinking in the past month, only male gender and age 21 or older were significantly associated with

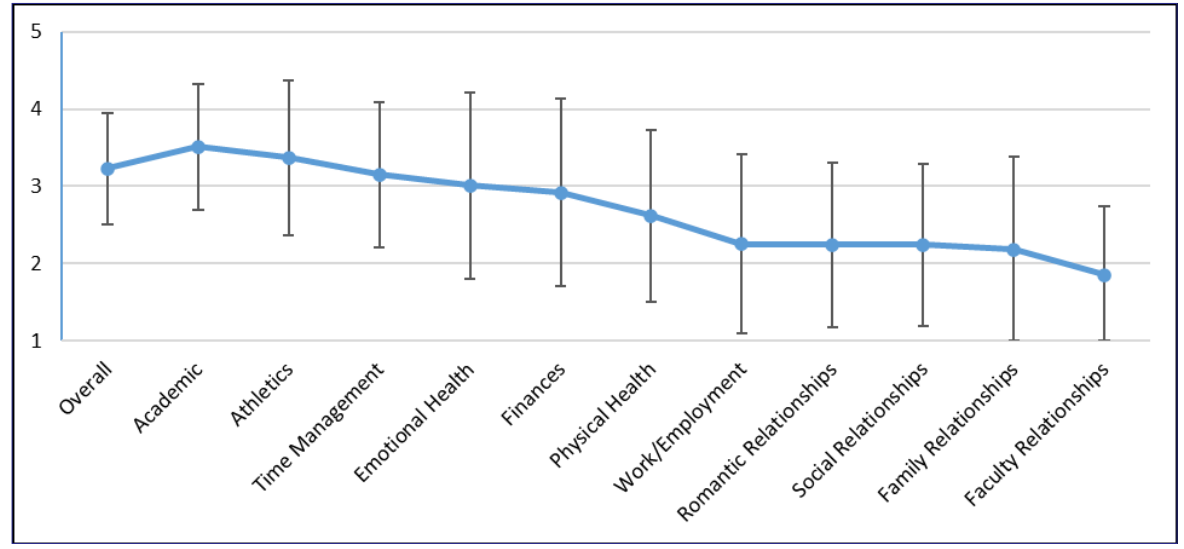

Figure 1

Student-Athlete Ratings of Intensity of Various Sources of Stress (N=188) 
binge drinking. In the final multivariable model, pain was also a significant predictor. In the final model, males had 3.22 higher odds of binge drinking than females $(95 \%$ CI $[1.31,7.90], p=.011)$; participants aged 21 or older had 2.55 higher odds of binge drinking $(95 \%$ CI $[1.12,5.79], p=.025)$; for each one point increase on the McGill Pain Questionnaire item assessing pain on a typical day in the last month, participants had 1.60 times higher odds of binge drinking $(95 \%$ CI [1.05, 2.44], $p=$ .028). Grade point average, stress, athletics-related anxiety, and perceived control of stressors were not associated with increased prevalence of binge drinking in either model (see Table 2).

\section{Table 2}

Factors Associated with Binge Drinking (six or more drinks) at Least Monthly $(N=188)$

\begin{tabular}{|c|c|c|c|c|}
\hline & $\begin{array}{c}\text { Binge Drinking, } \\
n(\%)\end{array}$ & $\begin{array}{c}\text { No Binge } \\
\text { Drinking, } n\end{array}$ & $\begin{array}{c}\text { Univariable } \\
\text { Analysis, } \\
\text { PrR (95\% CI) }\end{array}$ & $\begin{array}{l}\text { Multivariable } \\
\text { Analysis, } \\
\text { PrR (95\% CI) }\end{array}$ \\
\hline \multicolumn{5}{|l|}{ Gender } \\
\hline Female & $27(22.5 \%)$ & 93 & REF & REF \\
\hline Male & $17(44.7 \%)$ & 21 & $\begin{array}{l}2.79 \\
(1.29-6.02)^{* *}\end{array}$ & $\begin{array}{l}3.22 \\
(1.31-7.90) *\end{array}$ \\
\hline \multicolumn{5}{|l|}{ Age } \\
\hline$<21$ years old & $19(20.2 \%)$ & 75 & REF & REF \\
\hline \multirow[t]{2}{*}{$21-25$ years old } & $25(39.7 \%)$ & 38 & $\begin{array}{l}2.60 \\
(1.27-5.30)^{* *}\end{array}$ & $\begin{array}{l}2.55 \\
(1.12-5.79)^{*} \\
\end{array}$ \\
\hline & $\begin{array}{c}\text { Binge Drinking, } \\
\text { mean (IQR) }\end{array}$ & $\begin{array}{c}\text { No Binge } \\
\text { Drinking, mean } \\
\text { (IQR) }\end{array}$ & $\begin{array}{c}\text { Univariable } \\
\text { Analysis, } \\
\text { PrR (95\% CI) }\end{array}$ & $\begin{array}{c}\text { Multivariable } \\
\text { Analysis, } \\
\text { PrR (95\% CI) } \\
\end{array}$ \\
\hline $\begin{array}{c}\text { Grade Point } \\
\text { Average }\end{array}$ & $3.43(3.10-3.78)$ & $3.43(3.20-3.79)$ & $.971(.467-2.02)$ & $.909(.393-2.10)$ \\
\hline Stress (GSI) & $30.63(25-36)$ & $30.84(26-36)$ & $.996(.948-1.05)$ & $.979(.916-1.05)$ \\
\hline $\begin{array}{l}\text { Athletics-Related } \\
\text { Anxiety (SAS-2) }\end{array}$ & $27.19(21-33)$ & $26.48(21-31)$ & $1.01(.968-1.06)$ & $1.04(.977-1.10)$ \\
\hline $\begin{array}{l}\text { Physical Pain, Past } \\
\text { Month (SF- } \\
\text { MPQ) }\end{array}$ & $2.95(2-4)$ & $2.59(2-3)$ & $1.39(.992-1.96)$ & $\begin{array}{l}1.60(1.05- \\
2.44)^{*}\end{array}$ \\
\hline $\begin{array}{l}\text { Perceived Control } \\
\text { of Stressors } \\
\text { (PCQ) }\end{array}$ & $13.07(11-15)$ & $12.99(10-15)$ & $1.01(.905-1.12)$ & $1.05(.921-1.20)$ \\
\hline
\end{tabular}

Note. ${ }^{*} p<.05 .{ }^{*} p<.01 .{ }^{* *} p<.001$. PrR, prevalence ratio. CI, confidence interval. REF, reference category. IQR, interquartile range. 
Examining factors associated with cannabis use in the past 12 months revealed no significant predictors in the univariable analyses; however, in the final multivariable model, for each one point increase on the stress measure (GSI) there was a 7\% lower likelihood of using cannabis $(p=.048)$, and for each point higher on the athletics-related anxiety measure (SAS) there was a 7\% higher likelihood of cannabis use $(p=.028)$. No other variables were significantly associated with cannabis use in either the univariable or multivariable model (see Table 3 ).

\section{Table 3}

Factors Associated with Cannabis Use in the Past 12 Months $(N=188)$

\begin{tabular}{|c|c|c|c|c|}
\hline & $\begin{array}{l}\text { Used Cannabis, } \\
n(\%)\end{array}$ & $\begin{array}{l}\text { No Cannabis } \\
\text { Use, } n\end{array}$ & $\begin{array}{c}\text { Univariable } \\
\text { Analysis, } \\
\text { PrR (95\% CI) }\end{array}$ & $\begin{array}{c}\text { Multivariable } \\
\text { Analysis, } \\
\text { PrR (95\% CI) }\end{array}$ \\
\hline \multicolumn{5}{|l|}{ Gender } \\
\hline Female & $23(19.2 \%)$ & 97 & REF & \multirow{2}{*}{$\begin{array}{l}\text { REF } \\
2.02 \\
(.801-5.09)\end{array}$} \\
\hline Male & $12(30.8 \%)$ & 27 & $1.87(.827-4.25)$ & \\
\hline \multicolumn{5}{|l|}{ Age } \\
\hline$<21$ years old & $16(16.8 \%)$ & 79 & REF & \multirow{2}{*}{$\begin{array}{l}\text { REF } \\
2.19 \\
(.933-5.12)\end{array}$} \\
\hline \multirow[t]{2}{*}{$21-25$ years old } & $19(30.2 \%)$ & 44 & $2.13(.997-4.56)$ & \\
\hline & $\begin{array}{l}\text { Used Cannabis, } \\
\text { mean (IQR) }\end{array}$ & $\begin{array}{c}\text { No Cannabis } \\
\text { Use, mean (IQR) }\end{array}$ & $\begin{array}{c}\text { Univariable } \\
\text { Analysis, } \\
\text { PrR }(95 \% \mathrm{CI})\end{array}$ & $\begin{array}{c}\text { Multivariable } \\
\text { Analysis, } \\
\text { PrR (95\% CI) }\end{array}$ \\
\hline $\begin{array}{c}\text { Grade Point } \\
\text { Average }\end{array}$ & $3.36(3.00-3.61)$ & $3.45(3.20-3.80)$ & $.732(.351-1.52)$ & $\begin{array}{l}.725 \\
(.328-1.60) \\
\end{array}$ \\
\hline Stress (GSI) & $29.80(23-36)$ & $31.17(26-36)$ & $.974(.923-1.03)$ & $\begin{array}{l}.931 \\
(.867-1.00)^{*}\end{array}$ \\
\hline $\begin{array}{l}\text { Athletics-Related } \\
\text { Anxiety (SAS-2) }\end{array}$ & $28.43(22-34)$ & $26.16(21-31)$ & $1.04(.989-1.09)$ & $\begin{array}{l}1.07 \\
(1.01-1.13)^{*}\end{array}$ \\
\hline $\begin{array}{c}\text { Physical Pain, } \\
\text { Past Month } \\
\text { (SF-MPQ) }\end{array}$ & $2.74(2-4)$ & $2.70(2-3)$ & $1.04(.730-1.47)$ & $\begin{array}{l}1.07 \\
(.702-1.62)\end{array}$ \\
\hline $\begin{array}{l}\text { Perceived Control } \\
\text { of Stressors } \\
\text { (PCQ) }\end{array}$ & $12.97(11-15)$ & $12.98(11-15)$ & $.999(.890-1.12)$ & $\begin{array}{l}.977(.855- \\
1.12)\end{array}$ \\
\hline
\end{tabular}

Note. ${ }^{*} p<.05 .{ }^{*} p<.01 .{ }^{* * *} p<.001$. PrR, prevalence ratio. CI, confidence interval. REF, reference category. IQR, interquartile range.

For the univariable analysis assessing lifetime use of other substances aside from alcohol or cannabis, male gender and age 21 or older were significantly associated with substance use. In the final multivariable model, age was the only significant predictor, as participants 21 or older had 2.23 times higher odds of using a substance other than alcohol or cannabis $(95 \%$ CI $[1.01,4.91], p=.048)$. Grade point average, stress, athletics-related anxiety, physical pain, and perceived control of stressors were not associated with increased prevalence of substance use in either model (see Table 4). 


\section{Table 4}

Factors Associated with Lifetime Use of Substance other than Alcohol or Cannabis $(N=188)$

\begin{tabular}{|c|c|c|c|c|}
\hline & $\begin{array}{c}\text { Used } \\
\text { Substances, } n \\
(\%) \\
\end{array}$ & $\begin{array}{c}\text { No Substances, } \\
n\end{array}$ & $\begin{array}{c}\text { Univariable } \\
\text { Analysis, } \\
\text { PrR }(95 \% \text { CI }) \\
\end{array}$ & $\begin{array}{l}\text { Multivariable } \\
\text { Analysis, } \\
\text { PrR (95\% CI) }\end{array}$ \\
\hline Gender & & & & \\
\hline Female & $27(23.3 \%)$ & 89 & REF & REF \\
\hline Male & $17(43.6 \%)$ & 22 & $2.55(1.19-5.48)^{*}$ & $2.11(.900-4.95)$ \\
\hline $\begin{array}{l}\text { Age } \\
<21 \text { years old }\end{array}$ & $20(21.3 \%)$ & 74 & REF & REF \\
\hline \multirow[t]{2}{*}{ 21-25 years old } & $24(40.0 \%)$ & 36 & $2.47(1.21-5.04)^{*}$ & $\begin{array}{l}2.23 \\
(1.01-4.91)^{*}\end{array}$ \\
\hline & $\begin{array}{c}\text { Used } \\
\text { Substances, } \\
\text { mean (IQR) }\end{array}$ & $\begin{array}{l}\text { No Substances, } \\
\text { mean (IQR) }\end{array}$ & $\begin{array}{c}\text { Univariable } \\
\text { Analysis, } \\
\text { PrR }(95 \% \text { CI) }\end{array}$ & $\begin{array}{c}\text { Multivariable } \\
\text { Analysis, } \\
\text { PrR }(95 \% \text { CI) }\end{array}$ \\
\hline $\begin{array}{c}\text { Grade Point } \\
\text { Average }\end{array}$ & $3.30(3.00-3.60)$ & $\begin{array}{c}3.47(3.28- \\
3.80) \\
\end{array}$ & $.491(.227-1.06)$ & $.458(.203-1.04)$ \\
\hline Stress (GSI) & $30.36(25-36)$ & $31.22(26-36)$ & $.984(.937-1.03)$ & $1.00(.943-1.06)$ \\
\hline $\begin{array}{l}\text { Athletics-Related } \\
\text { Anxiety (SAS-2) }\end{array}$ & $25.59(19-30)$ & $27.11(21-33)$ & $.974(.930-1.02)$ & $.992(.937-1.05)$ \\
\hline $\begin{array}{l}\text { Physical Pain, Past } \\
\text { Month (SF- } \\
\text { MPQ) }\end{array}$ & $2.75(2-3)$ & $2.68(2-3)$ & $1.06(.764-1.47)$ & $1.05(.713-1.55)$ \\
\hline $\begin{array}{l}\text { Perceived Control } \\
\text { of Stressors } \\
\text { (PCQ) }\end{array}$ & $13.70(11-16)$ & $12.75(10-15)$ & $1.10(.984-1.23)$ & $\begin{array}{l}.1 .06(.936- \\
1.21)\end{array}$ \\
\hline
\end{tabular}

Note. ${ }^{*} p<.05 .{ }^{* *} p<.01 .{ }^{* * *} p<.001$. PrR, prevalence ratio. CI, confidence interval. REF, reference category. IQR, interquartile range.

In the Poisson regression model assessing alcohol- and drug-related risk behaviors, male gender, older age, and athletics-related anxiety were the three significant predictors in both the univariable and multivariable models (see Table 2). Grade point average was significant in the multivariable model only. In the final multivariable model, male gender accounted for a $.368 \mathrm{log}$ count increase in CRAFFT score $(p=.002)$, older age accounted for a $.318 \log$ count increase $(p=.008)$, each point on the SAS-2 accounted for a $.018 \log$ count increase $(p=.036)$, and each full-point increase in grade point average accounted for a 176 log count decrease in CRAFFT score $(p=.044)$. Stress, physical pain, and perceived control of stressors were not associated with alcohol- and drug-related risk in either model (see Table 5). 


\section{Table 5}

Factors Associated with Number of Items Endorsed on the CRAFFT, Indicating Alcohol-and Drug-Related Risk Behaviors $(N=188)$

\begin{tabular}{|c|c|c|c|}
\hline & $\begin{array}{l}\text { \#CRAFFT Items } \\
\text { Endorsed, mean }\end{array}$ & $\begin{array}{l}\text { Univariable Analysis, } \\
\operatorname{PrR}(95 \% \mathrm{CI})\end{array}$ & $\begin{array}{l}\text { Multivariable Analysis, } \\
\text { PrR (95\% CI) }\end{array}$ \\
\hline \multicolumn{4}{|l|}{ Gender } \\
\hline Women & 2.17 & REF & REF \\
\hline Men & 3.13 & $.362(.116-.608) * *$ & $.368(.135-.601)^{* *}$ \\
\hline \multicolumn{4}{|c|}{. } \\
\hline$<21$ years old & 2.05 & REF & REF \\
\hline $21-25$ years old & 2.91 & $.363(.134-.592)^{* *}$ & $.318(.084-.553)^{* *}$ \\
\hline & & $\begin{array}{l}\text { Univariable Analysis, } \\
\text { PrR (95\% CI) }\end{array}$ & $\begin{array}{c}\text { Multivariable Analysis, } \\
\text { PrR (95\% CI) }\end{array}$ \\
\hline $\begin{array}{l}\text { Grade Point } \\
\text { Average }\end{array}$ & & $-.109(-.297-.079)$ & $-.176(-.348--.005)^{*}$ \\
\hline Stress (GSI) & & $.010(-.007-.026)$ & $-.004(-.022-.014)$ \\
\hline $\begin{array}{l}\text { Athletics-Related } \\
\text { Anxiety (SAS-2) }\end{array}$ & & $.018(.003-.034)^{*}$ & $.018(.001-.036)^{*}$ \\
\hline $\begin{array}{l}\text { Physical Pain, } \\
\text { Past Month } \\
\text { (SF-MPQ) }\end{array}$ & & $.075(-.009-.040)$ & $.073(-.039-.186)$ \\
\hline $\begin{array}{l}\text { Perceived Control } \\
\text { of Stressors } \\
\text { (PCQ) }\end{array}$ & & $-.019(-.052-.014)$ & $-.014(-.046-.018)$ \\
\hline
\end{tabular}

Note. ${ }^{*} p<.05 .{ }^{*} p<.01 .{ }^{* * *} p<.001$. PrR, prevalence ratio. CI, confidence interval. REF, reference category.

\section{Discussion}

The purpose of our study was to examine the role of athletics-related stress and other factors that may be associated with alcohol and substance use among student-athletes. In this sample of student-athletes in five Upper Midwest states, rates of binge drinking and cannabis use were similar to national samples of student-athletes (NCAA, 2018a; NIAAA, 2020). Lifetime misuse of prescription opioids in our study was disconcertingly high at $12 \%$ (compared to $9 \%$ in a nationwide study), and misuse of stimulants was $11 \%$ (compared to $16 \%$ nationwide) (Phillips \& McDaniel, 2018). Similar to prior studies of college-aged adults and student-athletes, rates of binge drinking and substance use were substantially higher among males and older student-athletes (NCAA, 2018a; NIDA, 2019).

Being over 21, male gender, lower GPA, increased pain, higher perceived stress, and higher athletics-related anxiety were associated with increased alcohol and drug use and associated risk behaviors, although some factors (i.e., pain, stress, GPA) were only associated with outcomes in multivariable models. These findings are congruent with prior research on sociodemographic risk factors for substance use among student-athletes (Boyes et al., 2017; Denham, 2014; Lisha et al., 2011). It may be beneficial for future substance use interventions to target sociocultural factors such as stressors, peer behavior, and norms related to masculinity among student-athletes (Druckman et al., 2015; Iwamoto et al., 2014; Loughran, 2018). The relationship 
between substance use and grade point average may be bidirectional, and thus important to examine as it relates to academic-related stress, which was the highest rated source of stress in this sample.

The high rate of prescription drug abuse in this sample is particularly striking in the context of our national opioid epidemic; opioids contributed to 46,802 overdose deaths in 2018 (CDC, 2018). More than half of our sample of student-athletes had experienced physical pain in the past 30 days from an injury sustained while participating in athletics, and nearly two-thirds had experienced more than mild pain on a typical day in the last month. Given the high rates of physical pain, overall substance use, and prescription drug misuse among student-athletes, it is critical for medical providers to reassess their prescribing patterns for athletes experiencing physical pain in order to prevent addiction and its long-term consequences.

The American College Health Association recommends avoiding opioid prescription to college-aged patients whenever possible and provides guidance on prescribing practices, including non-opioid medications and pain management strategies, clearly communicating opioid risks to patients, and monitoring signs of abuse or dependence (ACHA, 2016). In July of 2018, the NCAA held a two-day Summit on Pain Management in College Athletes to review the state of the evidence and serve as a "springboard for subsequent peer-reviewed publications and educational documents" (NCAA, 2018b, p. 114); however, few actionable items or policies resulted from the summit, and the NCAA has not incorporated monitoring of opioid prescribing practices as a part of its drug testing program (Benavides, 2019).

In addition, research is needed to explore methods to intervene on the relationship between athletics-related anxiety and substance use. It is possible that athletics-related anxiety increases substance use. Athletics was rated as the second greatest source of stress in the lives of student-athletes in this sample, trailing only academic stress and exceeding stress related to emotional health, finances, and relationships. Among risk behaviors, the most common was using alcohol or drugs as a way to relax or feel better about oneself. It appears that student-athletes may engage in substance use as a form of maladaptive coping for athletics-related anxiety, and future studies should assess student-athlete coping styles to examine this relationship more directly. It is also possible that negative consequences of substance use on health and performance may increase athletics-related anxiety, and longitudinal and qualitative research is needed to explore this possibility (McDuff \& Baron, 2005).

Additional risk behaviors were also extremely common, including forgetting things that had happened while using alcohol or drugs, driving or riding in a vehicle with someone who was using alcohol or drugs, and drinking or using drugs alone. Each of these behaviors can serve as a warning sign of potential addiction, and driving or riding in a car while using substances is a well-documented public health and safety concern. College athletics departments, universities, and the NCAA/NJCAA would all benefit from a review of the existing evidence for the prevention, identification, and treatment of substance use disorders among young adults. Promising intervention models could be adapted to meet the unique characteristics and needs of student-athletes. 


\section{Limitations}

This study was conducted with student-athletes from six colleges and universities from five Upper Midwest states. We received a near-equal number of responses from athletes at the NCAA DI, DII, and DIII levels. Although we made an effort to recruit a similar number of students from NJCAA community colleges, we had a much lower response rate from these programs. Future studies may seek to reach out specifically to these schools with alternative recruitment strategies

Our sample was quite homogenous with regard to race and sexual orientation, with $88 \%$ of participants self-identifying as white and $96 \%$ self-identifying as heterosexual. As a result, it was not advisable to include these characteristics in our regression models due to concern about generalizing group-level risk based on a small number of cases. Our sample was also predominantly female. Some of these patterns reflect the actual demographics of student-athletes at the colleges we sampled but could also represent self-selection bias, as students who did not identify with these groups may have been less likely to choose to participate in the study. It will be critical for future studies to assess whether similar patterns of risk are present in a larger sample of student-athletes who are male, non-white, and non-heterosexual.

Similar to many studies using Internet recruitment, our response rate among invited students was fairly low. Additionally, all measures on the study relied on self-report, which can lead to social desirability bias. To minimize this challenge, we did not collect personally identifying information (e.g., names, email addresses) as part of the survey and reassured participants that their responses would remain anonymous; however, measures of illicit or socially stigmatized behaviors, and substance use in particular, may be susceptible to underreporting (Johnson, 2014).

\section{Conclusions}

The college years are a critical period during which experiences with substance use can contribute to the emergence of alcohol and substance use disorders. The social culture of college athletics may reinforce use patterns, and our study observed high levels of binge drinking, marijuana use, and other substance use in this sample of student-athletes. College student-athletes are highly susceptible to orthopedic injuries and associated pain, which often leads to early exposure to opioid pain medications with high potential for abuse. A strikingly high number of student-athletes in our sample endorsed abusing prescription opioids, and athletics departments must acknowledge and embrace their role in stemming harmful patterns of opioid use and addiction. Additionally, the pressures and anxieties of participating in college athletics, and the use of substances as a form of maladaptive coping, has been an understudied area. Athletes, coaches, and parents should continue to attend to emotional wellness among student-athletes to facilitate positive coping. Future interventions should continue to target the social contributors of substance use among student-athletes, particularly among men and those over 21 , the pathway to opioid use disorders, and untreated anxiety as a potential contributor to substance use. 


\section{References}

ACHA. (2016). Opioid Prescribing in College Health. American College Health Association. https://www.acha.org/documents/resources/guidelines/ACHA_Opioid_Prescribing_in_College_Health.pdf

Auerbach, R. P., Mortier, P., Bruffaerts, R., Alonso, J., Benjet, C., Cuijpers, P., Demyttenaere, K., Ebert, D. D., Green, J. G., Hasking, P., Murray, E., Nock, M. K., Pinder-Amaker, S., Sampson, N. A., Stein, D. J., Vilagut, G., Zaslavsky, A. M., \& Kessler, R. C. (2018). WHO World Mental Health Surveys International College Student Project: Prevalence and distribution of mental disorders. Journal of Abnormal Psychology, 127(7), 623-638. https://doi.org/10.1037/abn0000362

Bastien, C. H., Ellis, J. G., Athey, A., Chakravorty, S., Robbins, R., Knowlden, A. P., Charest, J., \& Grandner, M. A. (2019). Driving after drinking alcohol associated with insufficient sleep and insomnia among student athletes and non-athletes. Brain Sciences, 9(2). https://doi.org/10.3390/brainsci9020046

Benavides, O. (2019). Prevention and Treatment of Opioid Abuse in Collegiate Athletes. Board of Certification for the Athletic Trainer. https://www.bocatc.org/ newsroom/prevention-and-treatment-of-opioid-abuse-in-collegiate-athletes?category_key=at

Bird, M. D., Chow, G. M., \& Cooper, B. T. (2020). Student-athletes' mental health help-seeking experiences: A mixed methodological approach. Journal of College Student Psychotherapy, 34(1), 59-77. https://doi.org/10.1080/87568225.2 018.1523699

Bird, M. D., Chow, G. M., \& Yang, Y. (2020). College students' attitudes, stigma, and intentions toward seeking online and face-to-face counseling. Journal of Clinical Psychology, 76(9), 1775-1790. https://doi.org/10.1002/jclp.22956

Boyes, R., O’Sullivan, D. E., Linden, B., McIsaac, M., \& Pickett, W. (2017). Gender-specific associations between involvement in team sport culture and canadian adolescents' substance-use behavior. SSM - Population Health, 3, 663-673. https://doi.org/10.1016/j.ssmph.2017.08.006

Brown, G. T., Hainline, B., Kroshus, E., \& Wilfert, M. (2014). Mind, body and sport: Understanding and supporting student-athlete mental wellness (p. 120). NCAA. https://www.ncaapublications.com/productdownloads/MindBodySport.pdf

Buckman, J. F., Farris, S. G., \& Yusko, D. A. (2013). A national study of substance use behaviors among NCAA male athletes who use banned performance enhancing substances. Drug and Alcohol Dependence, 131(0), 50-55. https://doi. org/10.1016/j.drugalcdep.2013.04.023

Bush, K., Kivlahan, D. R., McDonell, M. B., Fihn, S. D., \& Bradley, K. A. (1998). The AUDIT alcohol consumption questions (AUDIT-C): An effective brief screening test for problem drinking. Ambulatory Care Quality Improvement Project (ACQUIP). Alcohol Use Disorders Identification Test. Archives of Internal Medicine, 158(16), 1789-1795. https://doi.org/10.1001/archinte.158.16.1789

CDC. (2018). Multiple Cause of Death, 1999-2018. Centers for Disease Control and Prevention National Center for Health Statistics. https://wonder.cdc.gov/controller/datarequest/D77 
de Grace, L. A., Knight, C. J., Rodgers, W. M., \& Clark, A. M. (2017). Exploring the role of sport in the development of substance addiction. Psychology of Sport and Exercise, 28, 46-57. https://doi.org/10.1016/j.psychsport.2016.10.001

Denham, B. E. (2014). High school sports participation and substance use: Differences by sport, race, and gender. Journal of Child \& Adolescent Substance Abuse, 23(3), 145-154. https://doi.org/10.1080/1067828X.2012.750974

Dijkstra, M. T. M., \& Homan, A. C. (2016). Engaging in rather than disengaging from stress: Effective coping and perceived control. Frontiers in Psychology, 7, 1415. https://doi.org/10.3389/fpsyg.2016.01415

Downey, R. G., \& King, C. (1998). Missing data in Likert ratings: A comparison of replacement methods. The Journal of General Psychology, 125(2), 175-191. https://doi.org/10.1080/00221309809595542

Druckman, J. N., Gilli, M., Klar, S., \& Robison, J. (2015). Measuring drug and alcohol use among college student-athletes. Social Science Quarterly, 96(2), 369380. https://doi.org/10.1111/ssqu. 12135

Ford, J. A., \& Arrastia, M. C. (2008). Pill-poppers and dopers: A comparison of non-medical prescription drug use and illicit/street drug use among college students. Addictive Behaviors, 33(7), 934-941. https://doi.org/10.1016/j.addbeh.2008.02.016

Graupensperger, S. A., Benson, A. J., \& Blair Evans, M. (2018). Everyone else is doing it: The association between social identity and susceptibility to peer influence in NCAA athletes. Journal of Sport \& Exercise Psychology, 40(3), 117127. https://doi.org/10.1123/jsep.2017-0339

Hatteberg, S. (2020). "There's no way I can do all of this": The Perceived impacts of stress exposure on the academic development of collegiate athletes. Journal of Issues in Intercollegiate Athletics, Fall 2020 Special Issue, 7-28.

Hazelden Betty Ford Foundation. (2015). Youth Opioid Study: Attitudes and Usage Young Adults Ages 18 to 24 in the United States. https://www.hazeldenbettyford. org/about-us/news-media/press-release/2015-opioid-use-among-college-youth

Iwamoto, D. K., Corbin, W., Lejuez, C., \& MacPherson, L. (2014). College men and alcohol use: Positive alcohol expectancies as a mediator between distinct masculine norms and alcohol use. Psychology of Men \& Masculinity, 15(1), 29-39. https://doi.org/10.1037/a0031594

Johnson, T. P. (2014). Sources of error in substance use prevalence surveys. International Scholarly Research Notices, 2014, 923290. https://doi. org/10.1155/2014/923290

Judge, L. W., Bell, R. J., Theodore, R., Simon, L., \& Bellar, D. (2012). An exploratory examination of burnout in NCAA Division II Athletes. Journal of Intercollegiate Sport, 5(2), 230-240. https://doi.org/10.1123/jis.5.2.230

Kern, A., Heininger, W., Klueh, E., Salazar, S., Hansen, B., Meyer, T., \& Eisenberg, D. (2017). Athletes connected: Results from a pilot project to address knowledge and attitudes about mental health among college student-athletes. Journal of Clinical Sport Psychology, 11(4), 324-336. https://doi.org/10.1123/ JCSP.2016-0028 
Knight, J. R., Sherritt, L., Shrier, L. A., Harris, S. K., \& Chang, G. (2002). Validity of the CRAFFT substance abuse screening test among adolescent clinic patients. Archives of Pediatrics \& Adolescent Medicine, 156(6), 607-614. https://doi. org/10.1001/archpedi.156.6.607

Kowalski, K.C. (2000). Development and validation of the Coping Function Questionnaire for adolescents in sport. University of Saskatchewan. https://harvest. usask.ca/handle/10388/etd-10212004-002424

Kowalski, Kent C., \& Crocker, P. R. E. (2001). Development and validation of the Coping Function Questionnaire for adolescents in sport. Journal of Sport \& Exercise Psychology, 23(2), 136-155.

Kutner, M., Nachtsheim, C., \& Neter, J. (2013). Applied Linear Statistical Models (5th ed.). McGraw-Hill.

Kwan, M., Bobko, S., Faulkner, G., Donnelly, P., \& Cairney, J. (2014). Sport participation and alcohol and illicit drug use in adolescents and young adults: A systematic review of longitudinal studies. Addictive Behaviors, 39(3), 497-506. https://doi.org/10.1016/j.addbeh.2013.11.006

Lewis, T. F., Milroy, J., Wyrick, D., Hebard, S. P., \& Lamberson, K. A. (2017). Binge-drinking and non-binge-drinking student-athletes: The role of proximal norms, negative expectancies, and selected sociodemographic variables. Journal of Child \& Adolescent Substance Abuse, 26(2), 141-151. https://doi.org/10. 1080/1067828X.2016.1222978

Lisha, N. E., Martens, M., \& Leventhal, A. M. (2011). Age and gender as moderators of the relationship between physical activity and alcohol use. Addictive Behaviors, 36(9), 933-936. https://doi.org/10.1016/j.addbeh.2011.04.003

Lisha, N. E., \& Sussman, S. (2010). Relationship of high school and college sports participation with alcohol, tobacco, and illicit drug use: A review. Addictive Behaviors, 35(5), 399-407. https://doi.org/10.1016/j.addbeh.2009.12.032

Lopes Dos Santos, M., Uftring, M., Stahl, C. A., Lockie, R. G., Alvar, B., Mann, J. B., \& Dawes, J. J. (2020). Stress in academic and athletic performance in collegiate athletes: A narrative review of sources and monitoring strategies. Frontiers in Sports and Active Living, 2(42), 1-10. https://doi.org/10.3389/fspor.2020.00042

Loughran, T. (2018). An examination of student-athlete stress and risky alcohol use. UNLV Theses, Dissertations, Professional Papers, and Capstones. https://doi. org/10.34917/14139882

McDuff, D. R., \& Baron, D. (2005). Substance use in athletics: A sports psychiatry perspective. Clinics in Sports Medicine, 24(4), 885-897, ix-x. https://doi. org/10.1016/j.csm.2005.06.004

Melzack, R. (1987). The short-form McGill Pain Questionnaire. Pain, 30(2), 191197. https://doi.org/10.1016/0304-3959(87)91074-8

National Institute on Drug Abuse. (2012). Resource Guide: Screening for Drug Use in General Medical Settings. National Institute on Drug Abuse. https://www. drugabuse.gov/sites/default/files/pdf/nmassist.pdf 
National Institute on Drug Abuse. (2020). Drugs, Brains, and Behavior: The Science of Addiction. National Institute on Drug Abuse. https:/www.drugabuse.gov/ publications/drugs-brains-behavior-science-addiction/drug-misuse-addiction

NCAA. (2018a). National Study on Substance Use Habits of College Student-Athletes. National Collegiate Athletics Association. http://www.ncaa.org/sites/default/files/2018RES_Substance_Use_Final_Report_FINAL_20180611.pdf

NCAA. (2018b). Summary of the NCAA Summit on Pain Management in College Athletes. National Collegiate Athletics Association. http:/www.ncaa.org/sites/ default/files/Jul2018SSI_PainSummit_Executive\%20Summary_20180910.pdf

NIAAA. (2020). College Drinking Fact Sheet. National Institute on Alcohol Abuse and Alcoholism. https://www.niaaa.nih.gov/sites/default/files/Collegefactsheet. pdf

NIDA. (2019). Drug Use Trends Among College-Age Adults (19-22): 2018 Monitoring the Future College Students and Young Adults Survey Results. National Institute on Drug Abuse. https://www.drugabuse.gov/drug-topics/trends-statistics/ infographics/drug-alcohol-use-in-college-age-adults-in-2018

Papanikolaou, Z., Nikolaidis, D., Patsiaouras, A., \& Alexopoulos, P. (2003). Commentary: The freshman experience: High stress-low grades. Athletic Insight: The Online Journal of Sport Psychology, 5(4), No Pagination Specified-No Pagination Specified.

Parisi, C. E., Bugbee, B. A., Vincent, K. B., Soong, A. M., \& Arria, A. M. (2019). Risks associated with alcohol and marijuana use among college student athletes: The case for involving athletic personnel in prevention and intervention. Journal of Issues in Intercollegiate Athletics, 12, 343-364.

Paule, A. L., \& Gilson, T. A. (2010). Current collegiate experiences of big-time, non-revenue, NCAA athletes. Journal of Intercollegiate Sport, 3(2), 333-347. https://doi.org/10.1123/jis.3.2.333

Phillips, E. L., \& McDaniel, A. E. (2018). 2018 College Prescription Drug Study. Center for the Study of Student Life, The Ohio State University. https://www. campusdrugprevention.gov/sites/default/files/2018\%20College $\% 20$ Prescription\%20Drug\%20Study.pdf

Reardon, C. L., \& Creado, S. (2014). Drug abuse in athletes. Substance Abuse and Rehabilitation, 5, 95-105. https://doi.org/10.2147/SAR.S53784

Rocha-Singh, I. A. (1994). Perceived stress among graduate students: Development and validation of the Graduate Stress Inventory. Educational and Psychological Measurement, 54(3), 714-727. https://doi.org/10.1177/0013164494054003018

Scholl, L., Seth, P., Kariisa, M., Wilson, N., \& Baldwin, G. (2019). Drug and opioid-involved overdose deaths-United States, 2013-2017. MMWR. Morbidity and Mortality Weekly Report, 67. https://doi.org/10.15585/mmwr.mm6751521e1

Sepúlveda, D. R., Thomas, L. M., McCabe, S. E., Cranford, J. A., Boyd, C. J., \& Teter, C. J. (2011). Misuse of prescribed stimulant medication for ADHD and associated patterns of substance use: Preliminary analysis among college students. Journal of Pharmacy Practice, 24(6), 551-560. https://doi. org/10.1177/0897190011426558 
Shrive, F. M., Stuart, H., Quan, H., \& Ghali, W. A. (2006). Dealing with missing data in a multi-question depression scale: A comparison of imputation methods. BMC Medical Research Methodology, 6(1), 57. https://doi.org/10.1186/14712288-6-57

Smith, R. E., Smoll, F. L., Cumming, S. P., \& Grossbard, J. R. (2006). Measurement of multidimensional sport performance anxiety in children and adults: The Sport Anxiety Scale-2. Journal of Sport \& Exercise Psychology, 28(4), 479-501. https://doi.org/10.1123/jsep.28.4.479

Veliz, P., Boyd, C. J., \& McCabe, S. E. (2017). Nonmedical use of prescription opioids and heroin use among adolescents involved in competitive sports. Journal of Adolescent Health, 60(3), 346-349. https://doi.org/10.1016/j. jadohealth.2016.09.021 